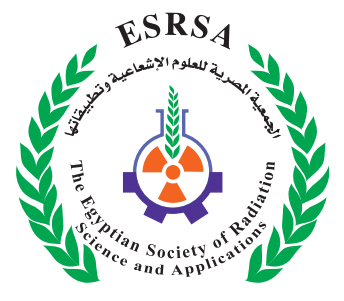

J. Nucl. Tech. Appl. Sci., Vol. 8, PP. 135 : 143 (2020)

\title{
Assessment of Radiation Leakage from Diagnostic Rooms of Radiology Department of a Teaching Hospital in Kano, Northwestern Nigeria
}

Joseph, D.Z.; Uba, Z.S.; Garba, I.; Sidi, M.; Umar, M.S.; Shem, B. S.

Received: 13/02/2020

Accepted: 29/09/2020

DOI: $10.21608 /$ jntas.2020.23942.1018

E.mail:umar.sani888@gmail.com

\section{KEYWORDS}

Radiation, X-ray,

Leakage, Effective

Dose, Controlled area,

Uncontrolled Area.

\section{ABSTRACT}

Diagnostic x-radiation is an essential part of present-day medical practice being the largest contributor of irradiation to the general population. Therefore, routine checking of $\mathrm{x}$-ray tubes leakage is very important to ensure that leakage radiation at a one-meter distance from focus is less than $1 \mathrm{mR} / \mathrm{h}$. The measurement of background radiation was performed during normal departmental working hours: early in the morning before the machines were switched on, and after the machines were switched on. Exposures were performed using different exposure factors and the fall out radiation in both control and uncontrolled areas were also recorded. The highest equivalent dose rate was recorded in the uncontrolled area of room 2 , where the mean dose rate was $26.21 \mu \mathrm{Sv} / \mathrm{h}$ (in changing room) and $11.67 \mu \mathrm{Sv} / \mathrm{h}$ (behind the door), respectively. It follows the dose rate measured in the uncontrolled area of room 1, where the mean dose rate was $6.33 \mu \mathrm{Sv} / \mathrm{h}$ (behind the door), $2.96 \mu \mathrm{Sv} / \mathrm{h}$ (in changing room $\mathrm{B}$ ), and $1.56 \mu \mathrm{Sv} / \mathrm{h}$ (in changing room A), respectively. The lowest radiation dose was measured in both controlled and uncontrolled areas of CT-scan, where the mean dose rate was $0.17 \mu \mathrm{Sv} / \mathrm{h}$ and $0.16 \mu \mathrm{Sv} / \mathrm{h}$, respectively, simply because the room doors and wall are adequately lead-lined and protected. All values obtained in this study are within the permissible limit, except that for uncontrolled areas in x-ray rooms 1 and 2, where radiation dose rates were higher than the reference limit for public exposure.

1. Department of Radiography, Bayero University Kano-Kano, Nigeria. 


\section{INTRODUCTION}

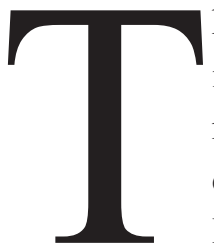

he application of ionizing radiation in medicine has greatly improved human health preservation through the diagnosis and treatment of diseases. Ionizing radiation also has wide applications in industries, agriculture, environmental monitoring, and water resources management and therefore forming an important tool for mankind (Kiragga, 2018). The largest contributor of irradiation to the general population comes from the diagnostic x-radiation. Although individual irradiations are usually low, there is a concern of possible excess cancer risk when large populations are irradiated. Unnecessary irradiations to patients from radiological procedures can be significantly reduced with rather small or no decrease in the value of medical diagnostic information. This can be achieved by using well-designed $\mathrm{x}$-ray equipment which is installed, used, and maintained by trained personnel, and by adopting standardized procedures (Chaloner, 1994). It cannot be ignored that the diagnostic $x$-ray procedures contribute to maximum population dose as compared to other man-made radiation sources. Therefore, the x-ray beam must be constricted to outside (both controlled and uncontrolled areas) of x-ray departments by protecting them with high shielding materials, such as lead (Bari et al., 2015).

Since the discovery of radiation, more than a century of radiation research has yielded extensive information on the biological mechanisms by which radiation can affect health. It is known that radiation can produce effects at the cellular level, causing their death or modification usually because of direct damage to deoxyribonucleic acid (DNA) strands in a chromosome. Based on their occurrence observation, health effects following a radiation exposure are defined here as either early or delayed health effects. Generally, early health effects are evident through the diagnosis of clinical syndromes in individuals, and delayed health effects, such as cancer, through epidemiological studies by observation of the increased occurrence of pathology in a considered population (UNEP, 2016).

The routine checking of x-ray tubes, diaphragm assemblies, and cones over several years has frequently revealed gross leaks of radiation. These have been due to the omission or shifting of the lead protection in the tube housing, or to the incorrect alignment of the diaphragm and cone assembly, or the use of materials of inadequate protective value (Ardran \& Kemp, 1956). The Monitoring of radiation doses received by staff in the radiology department is of great importance (Okaro et al., 2010). The purpose of a radiation monitoring program is to identify all sources of radiation exposure within an operation so that timely detection of changes in radiation parameters which may lead to increase the exposures and to produce sufficient information for optimization purpose (Samer et al., 2014).

Based on International Commission on Radiological Protection (ICRP) and International Atomic Energy Agency (IAEA) recommendations for the annual limit of effective dose to members of the general public that are in uncontrolled areas such as patients, visitors to the facility, and employees who do not work routinely with radiation sources, shielding designs should limit exposure to an effective dose that does not exceed $1 \mathrm{mSv}$ per single year. Radiologists are occupationally exposed to a low level of ionizing radiation during normal working. However, the dose level should not exceed $1 \mathrm{mSv}$ in a single year, with the maximum possible limit of $20 \mathrm{mSv}$ per year. As the dose level exceeds the specified limit, the probability of occurring cytogenetic abnormalities and fatal cancer risk for the clinical staff performing diagnostic procedures would increase (Bari et al., 2015).

As a result of radiological examinations, the exposure of radiation workers and the public due to scattered and leakage radiation is always increasing. Currently, there is no study conducted on the assessment of radiation leakage in the radiology depart- 
ment of Aminu Kano Teaching Hospital, from Kano, Northwestern Nigeria. Hence, there is a need to survey to ensure that the amount of leakage radiation from the $\mathrm{x}$-ray tube and the annual exposure limit to both radiation workers and members of the public coming to the department is within the permissible limit recommended by the ICRP.

\section{MATERIALS AND METHODS}

A prospective cross-sectional study was carried out between June 2019 to November 2019 using a radiation survey meter. The background radiation of all the radio-diagnostic rooms in the radiology department of Aminu Kano Teaching Hospital was measured, which includes: Three-conventional xray machines (Two located at the main new radiology complex and one at the old radiology complex), one-ceiling mounted $\mathrm{x}$-ray machine (located at the accident and emergency complex), one-digital radiography machine (DR), one-mammography machine, one-angiography machine, two-fluoroscopy machines (one at the new radiology complex and the other at Abdullahi Bayero complex, (ERCP) and 2-CT scans. However, one CT scanner is located at the main radiology complex, and the other (New CT) is located at Muhammadu Sunusi Radiodiagnostics, (MRSD)Complex. However, the design and layout of the old radiology complex, Accident and emergency unit, MRSD complex, ERCP were not captured in figure 1.

The study was conducted during normal departmental working hours. Early in the morning, before the machines were switched on, and after the machines were switched on, exposures were performed, and the fall out radiation was also recorded. The equivalent radiation dose rate was measured in specific locations selected according to rooms design as indicated in figure 1. These locations include: dose at one-meter distance from the x-ray tube, control panel, changing room, just behind the door and at the corridor outside the x-ray room (door closed). Three different exposure factors, for the most commonly anatomical structures examined in each unit were selected. For instance, in conventional x-ray room A, the factors selected were 110 peak kilovoltage, $(\mathrm{kVp})$ on 25 milliampere second (mAs), $75 \mathrm{kVp}$ on $12.5 \mathrm{mAs}$ and $60 \mathrm{kVp}$ on $4 \mathrm{mAs}$, which represent the exposure factors for lumbosacral, chest and extremities examination, respectively.



Fig. (1): Design and layout of the radiology department.

The radiation dose was monitored using a portable dosimeter, namely Thermo scientific FH 40 G Multi-purpose digital survey meter. The device is a wide range digital Geiger counter suitable for nearly all measurement tasks arising in radiation protection through optional plug and play probes available for neutron measurement, alpha and beta contamination reading and even to detect artificial gamma and $\mathrm{x}$ rays. Therefore, it was suitable for the current survey to detect and measure secondary radiation from $x$-ray at the control area, exact position of working radiographers, and uncontrolled area such as patient waiting area, changing room, dark room/digitizer and radiographer's office. Data recorded were analyzed using statistical package social sciences (SPSS), version 23.0, and the mean average exposure, standard deviation values were obtained.

\section{RESULTS AND DISCUSSION}

The various dose rate measured for different designated diagnostic rooms based on control area (CA), changing room one (CR1), changing room 
two (CR2), Behind the door (BD), Corridor (CRD), patient waiting Area (PWA), Darkroom (DR), Toilet (T) for different exposure factors were presented in tables below.
Table 1 below shows the dose rate values for location A (Static 1) when machine is operated at 60 $\mathrm{kVp}$ on $4 \mathrm{mAs}, 75 \mathrm{kVp}$ on $12.5 \mathrm{mAs}$ and $110 \mathrm{kVp}$ on $25 \mathrm{mAs}$ respectively.

Table (1): Dose rate values measured for diagnostic room A.

\begin{tabular}{|c|c|c|c|c|}
\hline \multirow{2}{*}{ STATIC 1 } & \multicolumn{3}{|c|}{ MEASURED DOSE RATE $(\boldsymbol{\mu S v} / \mathbf{h})$} & MEAN \pm SD \\
& $\mathbf{6 0} \mathbf{~ k V p , 4} \mathbf{~ m A s}$ & $\mathbf{7 5 k V p ~ , 1 2 . 5} \mathbf{~ m A s}$ & $\mathbf{1 1 0} \mathbf{~ k V p}$ on 25 mAs & \\
\hline Control Area & 0.18 & 0.18 & 0.56 & $0.31 \pm 0.22$ \\
\hline Changing Room (1) & 0.19 & 0.19 & 4.30 & $1.56 \pm 2.37$ \\
\hline Changing Room (2) & 0.19 & 0.28 & 8.40 & $2.96 \pm 4.71$ \\
\hline Behind the Door & 0.50 & 5.50 & 13.20 & $6.33 \pm 6.41$ \\
\hline Corridor & 0.27 & 0.29 & 0.98 & $0.34 \pm 0.10$ \\
\hline
\end{tabular}

Table 2 below shows the dose rate values for loon $70 \mathrm{kVp} 6 \mathrm{~ms}, 102 \mathrm{kVp} 12 \mathrm{~ms}$, and $133 \mathrm{kVp} 32$ cation B when machine is operated at fixed $200 \mathrm{~mA}$ ms respectively.

Table (2) : Dose rate values for Diagnostic room B.

\begin{tabular}{|c|c|c|c|c|}
\hline \multirow{2}{*}{ STATIC 2} & \multicolumn{3}{|c|}{ MESURED DOSE RATE $(\mu \mathrm{Sv} / \mathrm{h})$} & \multirow{2}{*}{$\operatorname{MEAN} \pm \mathbf{S D}$} \\
\hline & $70 \mathrm{kVp}, 6 \mathrm{~ms}$ & $102 \mathrm{kVp}, 12 \mathrm{~ms}$ & $133 \mathrm{kVp}, 32 \mathrm{~ms}$ & \\
\hline Control Area & 0.18 & 0.20 & 0.23 & $0.20 \pm 0.03$ \\
\hline Changing Room & 16.40 & 23.54 & 38.70 & $26.21 \pm 11.39$ \\
\hline Behind the Door & 0.21 & 13.01 & 21.80 & $11.67 \pm 10.86$ \\
\hline Corridor & 0.20 & 0.58 & 0.61 & $0.46 \pm 0.23$ \\
\hline
\end{tabular}

Table 3 below shows the dose rate values for Muhammadu Sunusi Radiodiagnostic Complex on $125 \mathrm{mAs}, 100 \mathrm{kVp}$ on $166 \mathrm{mAs}$ and $100 \mathrm{kVp}$ on (new CT) when the machine is operated at $120 \mathrm{kVp}$ $225 \mathrm{mAs}$ respectively.

Table (3) : Dose rate values for MSRD COMPLEX (new CT).

\begin{tabular}{|c|c|c|c|c|}
\hline $\begin{array}{c}\text { MSRD } \\
\text { COMPLEX } \\
\text { (new CT) }\end{array}$ & \multicolumn{3}{|c|}{ MESURED DOSE RATE $(\boldsymbol{\mu S v} / \mathbf{h})$} & MEAN \pm SD \\
\hline Control Area & 0.16 & 0.17 & 0.18 & $0.17 \pm 0.01$ \\
\hline Changing Room & 0.16 & 0.17 & 0.17 & $0.17 \pm 0.01$ \\
\hline Behind the Door & 0.15 & 0.15 & 0.17 & $0.16 \pm 0.01$ \\
\hline Patient Waiting Area & 0.15 & 0.15 & 0.16 & $0.16 \pm 0.01$ \\
\hline
\end{tabular}


Table 4 below shows the dose rate values for different locations within the Accident and emergency unit when the machine is operated at fixed $200 \mathrm{~mA}$ on $50 \mathrm{kVp} 0.2 \mathrm{~s}, 70 \mathrm{kVp} 0.3 \mathrm{~s}$, and $90 \mathrm{kVp} 0.4 \mathrm{~s}$ respectively.

Table (4) : Dose rate values for Accident and Emergency Unit.

\begin{tabular}{|c|c|c|c|c|}
\hline \multirow{2}{*}{$\begin{array}{c}\text { Accident \& Emergency } \\
\text { unit }\end{array}$} & \multicolumn{3}{|c|}{ MEASURED DOSE RATE $(\mu \mathrm{Sv} / \mathrm{h})$} & \multirow{2}{*}{$\mathbf{M E A N} \pm \mathbf{S D}$} \\
\hline & $50 \mathrm{kVp} 0.2 \mathrm{~s}$ & $70 \mathrm{kVp} 0.3 \mathrm{~s}$ & $90 \mathrm{kVp} 0.4 \mathrm{~s}$ & \\
\hline Control Area & 0.81 & 3.36 & 4.94 & $3.04 \pm 2.08$ \\
\hline Dark Room & 0.15 & 0.16 & 0.23 & $0.18 \pm 0.04$ \\
\hline Toilet & 0.17 & 0.23 & 0.32 & $0.24 \pm 0.08$ \\
\hline Call Room & 0.16 & 0.16 & 0.18 & $0.17 \pm 0.01$ \\
\hline Behind the Door & 0.14 & 0.14 & 0.15 & $0.14 \pm 0.01$ \\
\hline
\end{tabular}

Table 5 below shows the dose rate values for old chine is operated at fixed $200 \mathrm{~mA}$ on $70 \mathrm{kVp} 0.2 \mathrm{~s}, 80$ radiology complex for different locations when ma- $\mathrm{kVp} 0.4 \mathrm{~s}$, and $90 \mathrm{kVp} 0.6$ s respectively.

Table (5) : Dose rate values for Old radiology Complex.

\begin{tabular}{|c|c|c|c|c|}
\hline \multirow{2}{*}{$\begin{array}{c}\text { OLD RADIOLOGY } \\
\text { COMPLEX }\end{array}$} & \multicolumn{3}{|c|}{ MEASURED DOSE RATE $(\boldsymbol{\mu S v} / \mathbf{h})$} & MEAN \pm SD \\
\hline Control Area & $\mathbf{7 0} \mathbf{~ k V p ~} \mathbf{0 . 2} \mathbf{~ s}$ & $\mathbf{8 0} \mathbf{~ k V p ~ 0 . 4 ~ s}$ & $\mathbf{9 0} \mathbf{~ k V p ~ 0 . 6 ~ s}$ & \\
\hline Changing Room & 0.19 & 0.37 & 0.87 & $0.48 \pm 0.35$ \\
\hline Dark Room & 0.17 & 0.22 & 0.23 & $0.21 \pm 0.03$ \\
\hline Behind the Door & 0.17 & 0.20 & 0.33 & $0.23 \pm 0.09$ \\
\hline Patient Waiting Area & 0.15 & 0.16 & 0.19 & $0.17 \pm 0.02$ \\
\hline
\end{tabular}

Table 6 below shows the dose rate values for Abdullahi Bayero, Endoscopic retrograde cholangiopancreatography, (ERCP) when machine is oper-

ated at $68 \mathrm{kVp}$ on $3.2 \mathrm{mAs}, 70 \mathrm{kVp}$ on $6.4 \mathrm{mAs}$ and $75 \mathrm{kVp}$ on $75 \mathrm{mAs}$ respectively.

From table 1, for exposures factors $(60 \mathrm{KVp}$ and

Table (6): Dose rate values for ERCP Unit.

\begin{tabular}{|c|c|c|c|c|}
\hline \multirow{2}{*}{ ERCP UNIT } & \multicolumn{3}{|c|}{ MEASURED DOSE RATE $(\boldsymbol{\mu S v} / \mathbf{h})$} & MEAN \pm SD \\
& $\mathbf{6 8} \mathbf{~ k V p , ~ 3 . 2 ~ \mathbf { ~ A s }}$ & $\mathbf{7 0 k V p , 6 . 4} \mathbf{~ m A s}$ & $\mathbf{7 5} \mathbf{~ k V} \mathbf{p}, \mathbf{7 5} \mathbf{~ m A s}$ & \\
\hline Control Area & 0.18 & 0.20 & 0.22 & $0.20 \pm 0.02$ \\
\hline Toilet & 0.19 & 0.23 & 0.25 & $0.22 \pm 0.03$ \\
\hline Behind the Door & 0.17 & 0.18 & 0.19 & $0.18 \pm 0.01$ \\
\hline Patient Waiting Area & 0.15 & 0.15 & 0.17 & $0.16 \pm 0.01$ \\
\hline
\end{tabular}


Table (7) : X-ray Tube Leakage at One-Meter Distance in each Radio-Diagnostic Room.

\begin{tabular}{|c|c|c|c|c|c|c|}
\hline Location & $\begin{array}{c}\text { Static 1 } \\
(\mu \mathrm{Sv} / \mathrm{h})\end{array}$ & $\begin{array}{c}\text { Static 2 } \\
(\mu \mathrm{Sv} / \mathrm{h})\end{array}$ & $\begin{array}{c}\text { New CT } \\
(\mu \mathrm{S} v / \mathrm{h})\end{array}$ & $\begin{array}{c}\text { A\&E } \\
(\mu \mathrm{Sv} / \mathrm{h})\end{array}$ & $\begin{array}{c}\text { Old Site } \\
(\mu \mathrm{Sv} / \mathrm{h})\end{array}$ & $\begin{array}{c}\text { ERCP } \\
(\mu \mathrm{S} v / \mathrm{h})\end{array}$ \\
\hline Tube leakage & 8.24 & 13.96 & $* *$ & 0.24 & 5.33 & 0.16 \\
\hline
\end{tabular}

$4 \mathrm{mAs}$ and $75 \mathrm{kVp}$ on $12.5 \mathrm{mAs})$, protected cubicle and changing room (2) have lowest radiation dose rates, while the changing room (1), corridor and just behind the door have higher radiation dose. At exposure of (110 kVp on $25 \mathrm{mAs})$ only protected cubicle has the lowest radiation dose rate, which might be due to distance of this place from the x-ray source, as well as to the efficiency of the lead-lining of the area. The radiation dose rate is the highest being 3 times higher comparatively with that measured for changing room 1, and almost 2 times higher versus the one measured for changing room 2 which might be due to their closeness to the $\mathrm{x}$-ray source and probably some defects in a lead lining which protect the areas. When compared to other results from the literatures, it was found that the findings of this study are similar to those obtained by (Bari et al., 2015), (Samer et al., 2014), and (Malimban et al., 2018). The findings of our study contradict those obtained by (Owusu et al., 2018).

From table 2, for exposure factors $(200 \mathrm{~mA}$ on $70 \mathrm{kVp} 6 \mathrm{~ms}$ ), protected cubicle has the lowest radiation dose, which is at the level of background radiation. Dose rate just behind the main door and on corridor are slightly higher than the background radiation, while changing room has very high radiation dose. At this energy (200 mA on $102 \mathrm{kVp} 12 \mathrm{~ms}$ and $200 \mathrm{~mA}$ on $133 \mathrm{kVp} 32 \mathrm{~ms}$ ), dose rate in control cubicle is slightly higher than the background radiation but still within the acceptable limit, this is mainly due to distance of this place from the $\mathrm{x}$ ray source as well as the design of the x-ray room. Changing room, just behind the door and corridor has very high radiation dose which is due to their closeness to the x-ray source and most likely some defects in the shielding material protecting the areas.
These findings are similar to those obtained in the studies conducted by (Bari et al., 2015), (Samer et al., 2014), and (Malimban et al., 2018). The study results contradict those of the study conducted by (Owusu et al., 2018).

From table 3 , at all considered exposure factors $(120 \mathrm{kVp}$ on $125 \mathrm{mAs}, 100 \mathrm{kVp}$ on $166 \mathrm{mAs}$, and $100 \mathrm{kVp}$ on $225 \mathrm{mAs}$ ), no radiation leakage was detected, as all the values recorded were within the level of background radiation. The reason may be the distance of these places from the x-ray machine, as well as the design of the $\mathrm{x}$-ray room itself. This clearly showed that the CT Scan room is well designed and built, according to radiation protection criteria. These findings are similar to those of the study conducted by (Owusu et al., 2018), But they contradict the results obtained in the studies conducted by (Bari et al., 2015), (Samer et al., 2014), and (Malimban et al., 2018).

Table 4 shows that, for exposure factors (200 $\mathrm{mA}$ on $50 \mathrm{kVp} 0.2 \mathrm{~s}$ and $200 \mathrm{~mA}$ on $70 \mathrm{kVp} 0.3 \mathrm{~s}$ ), dark room, toilet, call room and just behind the door have the lowest radiation dose, which is within the level of background radiation, probably due to the low factors selected. Dose rate in the control cubicle slightly rises, might be probably due to some defects/ inefficiency in the shielding material protecting this area. At this energy level (300 mA on $90 \mathrm{kVp} 0.4 \mathrm{~s})$, dose rate in call room and just behind the door are still low (within the level of background radiation), may be due to the distance from the x-ray sources, as well as to the efficiency of the lead material used in the wall or door of these areas. However, very high radiation dose was recorded in toilet and control cubicle, simply due to inefficiency of lead material lining the areas. It was found that the findings of this 
study are similar to those of the studies conducted by (Bari et al., 2015), (Samer et al., 2014), and (Malimban et al., 2018), and contradict the results obtained in the study conducted by (Owusu et al., 2018).

From table 5, for exposure factors (200 mA on $70 \mathrm{kVp} 0.2 \mathrm{~s}$ ), no leakage radiation was detected, all the radiation dose values being within the level of background radiation, might be due to the low factors selected. for exposures done at $(200 \mathrm{~mA}$ on 80 $\mathrm{kVp} 0.4 \mathrm{~s}$ ), the dose rate in patient waiting area and just behind the door are still within the level of background radiation, which may be due to distance of these areas from the $\mathrm{x}$-ray machine, as well as to the efficiency of lead material used in walls or doors of the room. Dose rate measured in the changing room and dark room rises slightly comparatively with the background radiation, while the protected cubicle has the highest dose rate (nearly double) due to it closeness to the $x$-ray sources and some defect in the protective shielding. At this energy (200 mA on 90 $\mathrm{kVp} 0.6 \mathrm{~s}$ ), patient waiting area and just behind the door locations have the lowest dose, while changing room, dark room and protected cubicle has higher radiation dose rate compared to background radiation. The findings of this study are similar to those of the studies conducted by (Bari et al., 2015), (Samer et al., 2014), and (Malimban et al., 2018), and contradict the results of the study conducted by Owusu et al. (2018).

Also, for table 6 , for exposures done at $(68 \mathrm{kVp}$ on $3.2 \mathrm{mAs}$ ), no leakage radiation was detected, all the radiation dose rate values recorded being within the level of background radiation, may be due to the low factors selected. At exposure of $(70 \mathrm{kVp}$ on $6.4 \mathrm{mAs}$ ), radiation dose rate at patient waiting area and just behind the door are still within the level of background radiation, which may be due to the low factors selected. The dose rate in toilet and protected cubicle rises slightly comparatively with the background radiation. At exposure of $(75 \mathrm{kVp}$ on
$75 \mathrm{mAs}$ ), patient waiting area have the lowest dose rate, which is within the level of background radiation; this might be due to the low factors selected for the fluoroscopy machine. Even though the factors selected are low, dose rate in protected cubicle, toilet and just behind the door are slightly higher than the background radiation, these results indicating that the door leads to the room, toilet and protected cubicle were not efficiently lead lined. These findings are similar to those of the study conducted by (Owusu $e t$ al., 2018), but contradict the results obtained in the studies conducted by (Bari et al., 2015), (Samer $\boldsymbol{e t}$ al., 2014), and (Malimban et al., 2018).

Generally, the similarity and variation in the aforementioned findings with other results obtained in other studies might be likely due to distance of the radiation source from the control and uncontrolled areas, structure of radio-diagnostic facility itself and most likely due to adequate shielding of the diagnostics rooms design.

Table 7 shows the result of $\mathrm{x}$-ray tube leakage in all the unit except the new CT scan machine which was not assessed due to complex operating protocol of the installation. The result indicated that there was no tube leakage recorded in A\&E and ERCP radiodiagnostic machines, showing that the tube housing in these machines are well lead-lined, designed and may result in low radiation dose at different location in these rooms. Also, tube leakage in old site, static 1, and static 2 are much higher but still within reference level, this may be due to the omission or shifting of the lead protection in the tube housing, or incorrect alignment of the diaphragm and cone assembly, resulting in high radiation dose rate measured at various locations in these rooms.

Considering all the radio-diagnostic rooms, higher equivalent radiation dose was recorded in changing room and just behind the door of the static 2 locations, the values being $26.21 \mu \mathrm{Sv} / \mathrm{h}$ and 11.67 $\mu \mathrm{Sv} / \mathrm{h}$, respectively. It follows the radiation dose rates measured just behind the door, changing room 
(B) and changing room (A) of static 1, with values of $11.67 \mu \mathrm{Sv} / \mathrm{h}, 2.96 \mu \mathrm{Sv} / \mathrm{h}$ and $1.56 \mu \mathrm{Sv} / \mathrm{h}$, respectively. A higher effective dose rate was also found in the control cubicle of A\&E room (4.94 $\mu \mathrm{Sv} / \mathrm{h})$, may be due to inefficiency in the protected shielding of the area. The lowest equivalent dose rate was measured in the patient waiting area, just behind the door, changing room and protected cubicle of the CT-scan location, the values being $0.16 \mu \mathrm{Sv} / \mathrm{h}, 0.16 \mu \mathrm{Sv} / \mathrm{h}$, $0.17 \mu \mathrm{Sv} / \mathrm{h}$ and $0.17 \mu \mathrm{Sv} / \mathrm{h}$, respectively; the reason is simply because the doors and walls of the room are adequately lead lined, protected and the distance from the machine.

In summary, the study findings give adequate quality control information to radiographers, medical physicists or service engineers and can be used as a guide to perform more comprehensive monitoring procedures to ensure that all radio-diagnostic facilities are functioning more effectively.

\section{CONCLUSION}

The radiation tube leakage for all the assessed diagnostic rooms were within the reference level, permissible limit and recommended limit for public exposure and radiation workers. Hence the need to carry out quality control test for tube leakage in order to identified which part of the tube housing more radiation penetrate so that corrective measures can be taken. No conflict of interest.

\section{REFERENCES}

- Adam, A. (2013): Evaluation of radiation protection in $\mathrm{x}$ - ray rooms design in diagnostic radiological department in omdurman locality. Sudan Academy of Science Atomic Energy Council Institute of Radiation Safety, 46(38): 55.

- Ardran, G. and Kemp, F. (1956): Leakage Radiation from Diagnostic Tubes. British Med. J., 2(4983): 41.

- Bari, D.S.; Amin, P.M., and Abdulkareem, N.A. (2015): Measurement of the effective dose radiation at radiology departments of some hospitals in duhok governorate. J. Modern Phys., 6(05): 566.

- Chaloner, P. (1994): Diagnostic $x$-ray equipment compliance and facility survey: recommended procedures for equipment and facility testing. Ottawa, Canada: Environmental Health Directorate, Health Protection Branch.

- Choudhary, S. (2018): Deterministic and stochastic effects of radiation. Canc. Therapy \& Oncol. Int. J., 12(2): 1

- CNSC. (2012): Introduction to radiation ( $1^{\text {st }}$ edition). Ottawa: Canadian Nuclear Safety Commission.

- IAEA. (2004): Radiation, people and environment. ( $1^{\text {st }}$ edition). Vienna: International Commission on Radiological Protection.

- Kiragga, F. (2018): Effectiveness of the shielding mechanism in rooms housing $\mathrm{X}$-ray diagnostic eqauipment (a case study of mulago hospital, uganda). Int. J. Innov. Res. Adv. Eng., 5(2): 6.

- Malimban, J.; Johnson, S. and Baclig, A. (2018): Measurements of the scattered and leakage radiation in chest X-ray facilities. Physica Medica., 52(1): 134.

- Owusu, B.J.; Darko, E.O.; Charles, D.F.; Maruf, A.; Hanan, I. and Amoako, G. (2018): Scatter Radiation Dose Assessment in the Radiology Department of Cape Coast Teaching Hospital-Ghana. Open J. Radiol., 8(4): 299.

- Malone, J.F. (2009): The Design of Diagnostic Medical Facilities where Ionising Radiation is used. (1 $1^{\text {st }}$ edition). Dublin: Radiological Protection Institute of Ireland.

- Samer, A.Z.; Khadoura, K.J.; Yassin, S.S.; Al Agha, M.R.; Samin, Y., and Ayyub (2016): Ionizing radiation leakage and radiation protection measures in radio-diagnostic centers in governmental hospitals of gaza governorates, palestine. Asian Online Journal Publishing Group, 3(1).

- UEPA. (2012): Radiation: fact, risk and realities. ( $1^{\text {st }}$ edition). California: United State Environmental Agency 
- UNEP. (2016): Radiation: effect and source united nation environmental program. ( $1^{\text {st }}$ edition). Australia: United Nation Scientific Commitee. 